\title{
QUANDO OS DESCAMINHOS DA CORRUPÇÃO CRUZAM OS CAMINHOS DAS CRIANÇAS E DOS ADOLESCENTES: PERCEPÇÕES, RELAÇÕES POSSÍVEIS E IMPACTOS SOCIAIS
}

\author{
Leila Viviane Scherer Hammes \\ Universidade de Santa Cruz do Sul - UNISC - Brasil \\ André Viana Custódio \\ Universidade de Santa Cruz do Sul - UNISC - Brasil
}

\begin{abstract}
Resumo
A corrupção é um fenômeno global, presente desde os idos tempos na sociedade. Em virtude de sua capacidade mutacional esboçam-se conceitos amparados nas diferentes percepções que se tem acerca do assunto. Verifica-se que existem diferentes relações possíveis que podem ser estabelecidas entre os descaminhos da corrupção e os caminhos das crianças e dos adolescentes. Desde a primeira infância algumas práticas revelam a presença de atos corruptivos no contexto dos jovens. Consequentemente, diferentes impactos sociais podem ser evidenciados em virtude dos efeitos da corrupção. Assim, este artigo, baseia-se em pesquisa qualitativa e tem por objetivo verificar quais os impactos sociais da corrupção no que diz respeito às políticas públicas voltadas para crianças e adolescentes. Para tanto, será utilizada a técnica bibliográfica e o método dedutivo, que apontam as percepções, as relações possíveis e os impactos sociais. Concluindo-se que a educação é a principal ferramenta para desenvolver alguma mudança relacionada ao fenômeno da corrupção.
\end{abstract}

Palavras-chave: adolescente, corrupção, criança, impactos sociais, política pública

\section{Considerações iniciais}

Corrupção tem sido o assunto que perpassa todos os noticiários, brasileiros e internacionais. Certamente a mídia tem contribuído para informar, noticiar e denunciar situações ou fatos corruptivos. Chega-se a ter a impressão de que a corrupção é a doença da contemporaneidade.

Várias pesquisas e dados começam a ser organizados, mas não atingem a velocidade da corrupção e de suas novas formas. Algumas indicam que os mais pobres, os mais velhos e os 
mais jovens tendem a ser menos propensos a se corromper. Mas, não seriam eles justamente os mais afetados pelos reflexos da corrupção?

Nesse contexto, o presente artigo tem a pretensão de verificar quais os impactos sociais da corrupção no que diz respeito às políticas públicas voltadas para crianças e adolescentes.

Portanto, no primeiro momento serão apresentadas diferentes percepções acerca do fenômeno corrupção; no segundo momento buscar-se-á estabelecer as relações possíveis entre a corrupção, as crianças e os adolescentes; no terceiro momento serão apresentados os impactos sociais da corrupção frente às políticas públicas voltadas para as crianças e os adolescentes.

\section{Percepções da corrupção}

Conceituar a palavra corrupção por si só é tarefa árdua, possivelmente em virtude dos diferentes contornos ou caminhos que apresenta quando analisada na prática. $\mathrm{O}$ excerto de Carroll (2002, p. 59) ilustra perfeitamente o que se pretende dizer:

- O senhor poderia me dizer, por favor, qual o caminho que devo tomar para sair daqui?

- Isso depende muito de para onde você quer ir, respondeu o Gato.

- Não me importo muito para onde..., retrucou Alice.

- Então, não importa que caminho que você escolha, disse o Gato.

Quando se analisa o fenômeno corrupção é possível especular que qualquer caminho ou descaminho - serve para aquele que está disposto a essa prática. Ou como diria Alice, o lugar não importa muito. A corrupção está em todos os lugares e se apresenta sob diferentes roupagens, desde os idos tempos.

Nesse sentido, o filósofo-político Renato Janine Ribeiro (2015) explica que:

“Corrupção", entre os antigos, se referia à corrupção dos costumes. Seu grande exemplo era quando uma pessoa - ou uma cidade - abandonava os valores viris, austeros, exigentes, para se afeminar, entregando-se ao luxo e à complacência. A acusação a Sócrates é que, sempre perguntando, sempre questionando, ele corromperia a juventude, fazendo-a perder a crença nos deuses da cidade.

Assim, concordando com Ribeiro (2015), isso o que se fazia naquela época é para nós hoje filosofia, pensamento, liberdade, inteligência, é refletir sobre a vida. Naquela sociedade não era admissível abrir para a reflexão questões básicas da vida coletiva. Esse pensamento nos dias atuais permanece ainda em comunidades muito atrasadas.

Outra percepção de corrupção pode ser vista em Montesquieu que sustenta que a corrupção é encontrada em cada governo e normalmente começa pela corrupção dos princípios. Para esse pensador somente as leis poderiam corrigir a imoralidade por meio da coerção. Contudo, ao mesmo tempo, Montesquieu observa que o Estado a partir de uma Constituição 
pode se corrigir, se mantiver seus princípios, ou pode ser corrompido, se perder seus princípios (LEAL, 2013, p. 28-29).

Percebe-se a evolução do conceito corrupção, que antes estava vinculado aos costumes e agora se vincula aos princípios. A percepção da corrupção avança de acordo com as novas formas de corrupção que surgem e seus conceitos também seguem essa esteira. É “um fenômeno de múltiplos fundamentos e nexos causais, tratada por diversos campos do conhecimento [...] não sendo de fácil compreensão e definição" (LEAL, 2013, p. 80-81).

Atualmente a questão da corrupção aparece extremamente vinculada à questão da ética. É o que explica Leal (2013, p. 57):

\begin{abstract}
acredito que um dos principais desafios de uma Administração Pública que se queira ética é a de buscar mecanismos de fundamentação, de ação e de restabelecimento do equilíbrio da autonomia privada e da autonomia pública no cenário societal, eis que os objetivos e finalidades da República nacional só podem estar garantidos onde esteja assegurado/efetivado o princípio da soberania do povo, aqui entendido como o procedimento compartilhado comunitariamente à formação da vontade estatal.
\end{abstract}

Nesse contexto, Wolkmer (1990, p. 47) aponta como causas a organização social arcaica, as classes elitistas, os vícios de dominação, aos quais o Estado tem sido conivente e apoiado de forma indiscutível. Isso acaba por favorecer e a perpetuar as relações sociais fundadas no clientelismo, no apadrinhamento, no nepotismo, no coronelismo, na ética da malandragem e da esperteza, e, na infinidade de irregularidades e desvios no padrão cultural de comportamento do homem brasileiro.

É o que, de certa forma, Roberto da Matta (2009) resume como jeitinho brasileiro: em suma, o jeitinho se confunde com corrupção e é transgressão, porque ela desiguala
o que deveria ser obrigatoriamente trado com igualdade, ou seja, sem sine ira et
studio, como dizia Max Weber, roubando um adágio de Tácito. O que nos enlouquece
hoje no Brasil não é a existência do jeitinho como ponte negativa entre a lei e a pessoa
especial que dela se livra. É a persistência de um estilo de lidar com lei, marcadamente
aristocrático que de certo forma induz o chefe, o diretor, o dono, o patrão, o
governador, o presidente, a passar por cima da lei porque ele a "empossa". O cargo
público ainda hoje, e apesar dos avanços, ainda é concebido aristocraticamente, não
burocraticamente e patriarcalmente como o foi nos velhos tempos de Dom Casmurro.

O nosso "jeitinho brasileiro" está presente em todos os espaços revestindo-se em diferentes formas: furando a fila do banco, ficando com o troco que foi entregue a mais tendo percebido isso, fazendo transcrições diretas e indiretas nos trabalhos acadêmicos sem o respeito à fonte, dando "carteiraços" do tipo "você sabe com quem está falando", comprando - ou vendendo - votos entre tantos outros exemplos possíveis.

Mas há também o "jeitinho brasileiro" institucionalizado: a gorjeta, autorizada por dispositivo legal. Como explica Leal (2013, p. 16), a gorjeta não se caracteriza como ato corruptivo, pois não tem a intenção de obter de favores especiais por parte dos garçons, mas, 
sim, de reconhecer e agradecer o serviço realizado. Não há um sentido negativo, nem no ato de dar, nem no ato de receber a gorjeta.

Mas, questiona-se se em todos os momentos a gorjeta preserva a intenção de não obter favores especiais. E quando essa gorjeta for dada com o interesse de reservar a melhor mesa ou de ter atendimento preferencial em relação aos demais clientes não estaria sendo desvirtuada de sua finalidade? Certamente. Enfim, até o "jeitinho brasileiro" adquire novas roupagens frente à versatilidade da corrupção.

Embora se tenha a impressão de que nunca se falou tanto em corrupção no Brasil é preciso ter consciência que a corrupção é um fenômeno mundial. Nesse sentido Pereira (2003, p. 43) expõe que as práticas de corrupção não estão presentes somente nos países em desenvolvimento, mas também se desenvolvem em maior ou menor grau nos países desenvolvidos. A diferença existente na corrupção de países em desenvolvimento e em países desenvolvidos está na origem da corrupção e na dimensão do problema. Nesse sentido, esse autor explica que "nos países desenvolvidos a corrupção decorre de falhas nos sistemas democráticos, enquanto nos países em desenvolvimento a corrupção surge em decorrência das debilidades das instituições".

Portanto, enquanto que em países em desenvolvimento a corrupção pode ser motivada pelo excesso de burocracia - certamente uma das falhas mais notáveis - nos países desenvolvidos a motivação pode estar relacionada à falta de tenacidade da coerção. Pois certamente, países desenvolvidos que punem energicamente e exemplarmente seus corruptores têm índices de corrupção reduzidos.

Embora Pereira (2003, p. 43) entenda que o ato de corromper é um comportamento em que há o desvio dos deveres formais de uma função pública em virtude de interesses privados - vinculados a fatores pessoais, familiares ou de um grupo fechado - que têm o objetivo de obter pecúnia ou de melhorar o status. Percebe-se, cada vez mais, que a corrupção também está presente na vida privada, em situações que não guardam vínculo com a função pública, porém mantendo o mesmo fim (obtenção de vantagem).

Possivelmente amparada por entendimentos dessa linha, a Controladoria Geral da União - CGU entende que

a corrupção é um fenômeno social que tem grandes efeitos econômicos sobre a sociedade. Quando sistêmica e não combatida, ela se impõe como um imposto a ser pago pelos empresários para que tenham seu negócio viabilizado ou autorizado. Além disso, a corrupção afeta negativamente a competitividade dos produtos nacionais no comércio internacional ao elevar o custo do investimento produtivo e tornar o ambiente de negócios menos estável (BRASIL, 2009, p. 8). 
Considerando que o objetivo vinculado à corrupção é a obtenção de vantagens, especialmente pecuniárias, o resultado obtido não poderia ser outro senão aquele que afeta diretamente o cenário econômico e suas correlações com o mercado e com a sociedade. Assim, em decorrência da lei brasileira de anticorrupção, muitas empresas estão empenhadas na elaboração de códigos de ética, para se respaldarem frente a possíveis intempéries. Mas, de que adiantam códigos de ética quando não se tem ética?

Ética é um valor intrínseco. Portanto, cada vez mais é preciso buscar a conscientização das pessoas com o intuito e aperfeiçoar e consolidar esse conceito. A Lei Anticorrupção é um esforço nesse sentido. Assim como existem outros exemplos vinculados a organizações sociais que buscam a promoção de atitudes éticas e politicamente corretas.

Numa percepção teológica, Mário Sérgio Cortella (2015) ao reportar-se à passagem bíblica de São Paulo que diz que "tudo me é lícito, mas nem tudo me convém" e ao mencionar que Jesus diz que "nada adianta ao homem ganhar o mundo se perder a alma", questiona se isso vale para o Brasil de hoje e responde que:

Não podemos perder o foco do que vivemos hoje no Brasil, que não é o auge da
sujeira, mas o começo da limpeza. Existem plataformas digitais que favorecem o
combate ao ilícito, imprensa livre e uma democracia que não teme. O momento
favorece a novidade, que não é a corrupção, mas um começo da limpeza. O país vive
uma fase positiva, com a recusa ao apodrecimento ético. A palavra de Paulo serve
para cristãos e não cristãos, mas há outros pensadores inspiradores. O Evangelho
emite alertas para um país que está revendo seu modo de sustentação à base de cada
um por si e Deus por todos.

De fato, não se pode esquecer que há uma luz no fim do túnel. Afinal várias experiências têm logrado êxito e começam a contribuir para a limpeza mencionada por Cortella.

O fenômeno da corrupção normalmente é associado ao mundo adulto, mas será que existe alguma relação possível entre corrupção, crianças e adolescentes? É o que se passa a analisar.

\section{As relações possíveis entre a corrupção e as crianças e adolescentes}

Desde a tenra idade as crianças sabem o que é certo e o que é errado, o que podem e o que não podem fazer, o que é justo e o que é injusto. Nesse sentido, é interessante trazer o resultado de pesquisa ${ }^{1}$ realizada pela Universisdade de Manchester (Reino Unido), em parceria com o Max Planck Institute for Evolutionary Anthropology in Leipzig (Alemanha), mostrando que crianças de três a cinco anos apresentaram um nível de preocupação com o próximo e um senso intuitivo de justiça que surpreendeu os pesquisadores.

\footnotetext{
${ }^{1}$ Pesquisa mostra que crianças podem apresentar senso de justiça aos três anos. Zero Hora. Porto Alegre, 2015. Disponível em: বhttp://zh.clicrbs.com.br/rs/vida-e-estilo/vida/bem-estar/noticia/2015/06/pesquisa-mostra-quecriancas-podem-apresentar-senso-de-justica-aos-tres-anos-4784264.html>. Acesso em: 19 jun. 2015.
} 
Portanto, preliminarmente, é possível afirmar que elas compreendem o que sejam atos corruptivos, mesmo que estejam disfarçados ou encobertos, podendo concordar com os mesmos ou refutá-los, dependendo do senso de justiça que têm. Um exemplo é a ‘chantagem' que alguns pais fazem para que seus filhos almocem bem, prometendo um bombom ou um chocolate após o almoço. Ou os pais que prometem aquele brinquedo tão sonhado em troca de boas notas no boletim. Ou ainda um presente especial para sustentarem alguma mentira em prol dos pais.

E não é surpresa presenciar situações em que as crianças, especialmente, questionam seus pais perguntando se agindo dessa forma não estarão mentindo ou sendo injustos e são os próprios pais que explicam que em algumas situações é possível falsear a verdade, o que se chama por aí de mentira politicamente correta.

Constata-se uma primeira relação prática entre corrupção, crianças e adolescentes, eis que esses pequenos atos corruptivos são oriundos do próprio ambiente familiar e são ensinados pelos próprios pais.

Alcançando a adolescência esses jovens estão mais propensos a se corromper, talvez pelo fato de não temerem as consequências. E além de serem corrompidos passam a corromper outros jovens para, por exemplo, obter drogas ou armas ilícitas.

Esses fatos somente reforçam que

a corrupção é um dos grandes males que afetam a sociedade. São notórios os custos
políticos, sociais e econômicos que acarreta. Compromete a legitimidade política,
enfraquece as instituições democráticas e os valores morais da sociedade, além de
gerar um ambiente de insegurança no mercado econômico (BRASIL, 2009, p. 9).

Aliás, a corrupção além de afetar a sociedade como um todo, afeta de forma mais incisiva os direitos humanos. Indicadores demonstram que quanto maior os índices de corrupção nos países, menor os índices de atendimento aos direitos humanos. É o que afirma Lopes e Toyoshima (2013, p. 222):

de maneira geral, utilizando duas bases de dados diferentes, pode-se perceber que a
corrupção estadual tem influenciado negativamente a eficiência na prestação de
serviços de educação e saúde nas regiões do país, mesmo quando se olha para o nível
de instrução e de renda locais. De acordo com que os dados permitiram estimar, uma
elevação na proxy utilizada para a corrupção gera uma redução no escore de eficiência
técnica e, em termos do impacto da corrupção sobre os indicadores sociais analisados,
se a corrupção dobrasse em um estado tecnicamente eficiente, isto resultaria em
considerável redução do bem-estar geral da população.

Visualiza-se aqui uma segunda relação possível entre corrupção, crianças e adolescentes, pois os dois últimos são intimamente atingidos no que tange aos direitos humanos, eis que são sujeitos em condição peculiar de desenvolvimento.

Aliás, conforme leciona Leal (2013, p. 96), 
todos os indivíduos são dotados de Direitos Humanos, e todos os Estados estão obrigados em garantir que sua população usufrua destes Direitos. Por sua vez, cada Direito Humano tem a favor de si específicas obrigações por parte dos Estados e mesmo por parte dos indivíduos entre si; ocorre que, para as pessoas efetivamente usufruírem de seus Direitos Fundamentais, o Estado precisa cuidar para que haja condições favoráveis para tanto, assim é que se diz que os Estados precisam respeitar, proteger e fazer cumprir todos estes Direitos.

Logo, se todos os indivíduos são dotados de direitos humanos, as crianças e os adolescentes precisam ter garantidos direitos humanos para a sua formação. O que não ocorre de forma clara e evidente quando situações corruptivas afetam, por exemplo, as políticas públicas que visam justamente a garantir direitos humanos, como a educação, a saúde, a habitação, entre outros.

Nesse contexto, conforme afirmou Leal nas linhas acima, cabe aos governos fazer cumprir os direitos humanos e fundamentais para que as pessoas possam de fato usufruir o que lhes é de direito. Inusitado é o fato de que, em regimes democráticos, as pessoas que escolhem seus governos também podem ser vitimizadas por eles.

E para fazer cumprir os direitos humanos devem, dentre outras medidas, combater o que lhe retira a efetividade, isto é, combater a corrupção.

Lacca (s.d., p. 166) entende que "esta lucha contra la corrupción debe desplegarse en todos sus aspectos y en todas sus variantes; en todos sus tiempos; en la estructura y en la conyuntura; teniendo como piedra fundamental el ejemplo de los gobernantes".

De fato, é precisar empenhar muitos esforços e em diferentes esferas, para que se logre algum êxito no combate à corrupção. Talvez, o aspecto mais difícil seja a pedra fundamental mencionada por Llaca. Afinal, há inúmeros exemplos que comprovam que os governantes são os principais corruptores.

Mas essa pedra fundamental também é apontada por Pereira (2003, p. 15). Esse autor entende que para que se promova um combate efetivo à corrupção, é preciso que se tenha uma 'governança responsável', mobilização política e organização da sociedade civil para que se consiga controlar aqueles que detêm o poder. Alerta, ainda, esse autor, que "quando a corrupção se torna sistêmica, as medidas convencionais para combatê-la são insuficientes”. Como alternativa aponta a necessidade de conscientizar a sociedade civil, mostrando o que a corrupção custa.

Contudo, essa demonstração do que a corrupção custa também é eivada de vícios ou fragilidades. Pois, certamente somente será possível apresentar dados concretos relacionados a dados financeiros que foram 'perdidos' em desvios ou fraudes corruptivas. Isto porque os custos relacionados às consequências e aos resultados que não foram alcançados somente poderão ser 
estimados ou mostrados objetivamente. Por exemplo, numa licitação em que os remédios destinados a crianças com câncer não chegam aos postos de saúde, em virtude de fraude. Podese mostrar o valor contratado que não foi realizado. Pode-se noticiar a fraude. Mas, não há como avaliar o quanto a falta desse medicamento interferiu na vida de quem precisava e de quem estava ao seu lado.

Há ainda outro exemplo, qual seja a compra de vagas em escolas públicas. O fato em si pode ser mostrado, mas não há como apurar o quanto essa vaga comprada interferiu na vida de outro jovem (e de sua família) que talvez ficasse sem acesso à escola.

Leal (2013, p. 103-104) observa que essa prática consiste em violações que atingem todo o sistema de ensino. Seja pelo fato de interferirem na garantia da justiça social, que oferta ensino gratuito, fundamental e médio, de forma igual para todos que dele necessitem. Seja pelo fato de impactarem fortemente nas políticas públicas de inclusão social das crianças e dos adolescentes refletindo na formação desses jovens bem como na sua inserção no mercado de trabalho.

Evidencia-se que há várias relações possíveis entre corrupção, crianças e adolescentes, portanto, cabe também apresentar algumas reflexões relacionadas aos impactos sociais que a corrupção pode apresentar frente às políticas públicas voltadas para crianças e adolescentes.

\section{Os impactos sociais da corrupção frente às políticas públicas voltadas para as crianças e adolescentes}

Possivelmente a corrupção pode gerar infinitas formas de impactar socialmente na vida de crianças e adolescentes, simplesmente em virtude dos reflexos individuais que ocasiona.

Os meios de comunicação apresentam os exemplos, como no caso, recentemente noticiado, de uma quadrilha que fraudava licitações de merenda escolar em Sergipe ${ }^{2}$.

Ora, se recebem merenda é porque dela necessitam. Além disso, em outros momentos foi noticiado que muitas vezes a única refeição da criança é na escola. Mas como apurar o impacto social que a falta da merenda causou a essas crianças do Sergipe? É possível estimar a fome, em primeiro lugar, doenças e falta de interesse nos estudos, como algumas consequências imediatas, a falta de colocação no mercado de trabalho e o prosseguimento dos estudos em nível acadêmico, como consequências mediatas. Talvez essa seja uma das faces perversas da corrupção, pois além de não ser possível estimar totalmente seus efeitos eles ainda se prolongam ao longo do tempo.

\footnotetext{
${ }^{2}$ SBT denuncia quadrilha da merenda escolar em Sergipe- http://www.nenoticias.com.br/90376_sbt-denunciaquadrilha-da-merenda-escolar-em-sergipe-assista-agora.html
} 
Por isso, há de se concordar com Renato Janine Ribeiro (2014), quando ele afirma que o corrupto não rouba o supérfluo, mas o essencial.

É o que explica Leal (2014, p. 9-10). Quando a corrupção abrange tudo o que está relacionado à política e isso é tolerado, aceito, pela comunidade, as pessoas que mais sofrem são as mais necessitadas e as que sofrem os efeitos diretos da corrupção. Porque os efeitos da corrupção lhes tira o que é essencial. Os hospitais públicos deixam de prestar o devido atendimento em virtude do desvio de recursos destinados à saúde. As famílias que deixam de receber os recursos de programas sociais a elas destinados em virtude de sua situação de pobreza - ou de extrema pobreza. As escolas ficam sem recursos financeiros para adquirirem material escolar interferindo na qualidade da formação dos estudantes.

Com isso não se quer dizer que a causa da pobreza é a corrupção. A pobreza é causada por inúmeros fatores: políticos, econômicos, sócio-culturais, históricos, entre outros. Mas, que a corrupção aumenta consideravelmente os índices de pobreza e atinge diretamente quem mais necessita.

Os exemplos acima abrangem saúde, educação e fatores socioeconômicos, que atingem não só as famílias, mas também crianças e adolescentes, que sofrem duplamente os efeitos da corrupção. Pois além de sofrerem os impactos em virtude da pobreza, também sofrem porque não lhes é garantido o que é essencial para o seu desenvolvimento, deixando de ser observada a prioridade absoluta no atendimento de suas necessidades.

Outro impacto social, correlato aos acima destacados, está relacionado às taxas de mortalidade infantil. Os países ocidentais que tem os maiores indicadores de corrupção também são aqueles que têm as maiores taxas de mortalidade infantil. É o que revelam as recentes pesquisas do Fundo Monetário Internacional, envolvendo setenta e um países ocidentais (LEAL, 2014, p. 20-21).

A conclusão da Controladoria Geral da União também vai nessa esteira:

O fenômeno da corrupção, ao contrário do que se pensa, não afeta somente governos,
mas, também, indistintamente, cidadãos, entidades públicas e instituições privadas,
provocando a concorrência desleal, comprometendo o crescimento econômico e
afugentando novos investimentos. O país inteiro é prejudicado. Para controlar a
corrupção, é preciso conjugar esforços de cidadãos, empresas e governo para um
mesmo propósito: promover um ambiente de integridade na esfera pública e na esfera
privada (BRASIL, 2009, p. 7).

Esses contornos econômicos vão ocasionar falta de empregos, por exemplo. O que traz mais um impacto social, pois na medida em que os pais ou aquelas pessoas que dão o sustento a crianças e adolescentes não têm emprego, outras necessidades básicas serão sacrificadas. 
Outro possível impacto social é o trabalho infantil, quando crianças são mandadas para as esquinas pedir esmola ou são obrigadas a realizar trabalhos destinados aos adultos para poderem contribuir com o sustento de suas famílias. Isso para não citar exemplos mais trágicos.

Nesse sentido, conforme explica Custódio (2006, p. 179), a experiência histórica do Brasil demonstra o baixo nível de eficiência, a demora no atendimento e as oportunidades que se dá para o desvio de recursos, para o clientelismo e para a corrupção.

$\mathrm{Na}$ realidade o que verifica é um círculo vicioso, eis que a corrupção ao atingir diretamente uma área causa impactos a outras que com ela se relacionam. Por isso, ratifica-se o entendimento da Controladoria Geral da União, pois o país inteiro é prejudicado.

Como se demonstrou anteriormente muitos fatores podem dar causa à corrupção. Estruturas burocráticas podem facilitar e aumentar a possibilidade de praticar atos corruptivos. O envolvimento da população também pode ser determinante, por exemplo, ao reeleger um político sabidamente corrupto, questiona-se a qualidade da participação democrática. Por outro lado, a maior participação ativa da população na política desestimula a prática da corrupção (LOPES e TOYOSHIMA, 2013, p. 205).

Uma forma de participação poderia ser por meio de denúncias acerca de suspeitas ou fatos concretos relacionados à corrupção. Diferentes canais têm sido criados nesse intuito. Renato Janine Ribeiro (2014) destaca que esses controles e a facilitação de registros/denúncias criam um risco maior para os corruptos, pois sabem que há a possibilidade de que sua prática seja revelada. Pondera ainda que "a única forma de evitar isso é as pessoas estarem sem roupa e num lugar - como uma piscina ou o mar - em que aparelhos eletrônicos não possam ser utilizados"3.

Outra forma está relacionada às iniciativas privadas que começam a ganhar força no que tange ao combate à corrupção, de forma direta ou indireta. Um exemplo é a Fundação Abrinq, uma organização sem fins lucrativos, que tem como missão promover a defesa dos direitos e o exercício da cidadania de crianças e adolescentes. E, ao cumprir com sua missão, contribui, mesmo que de forma indireta, no combate à corrupção.

Interessante observar ainda a inter ou multidisciplinaridade que se estabelece no combate à corrupção. A área da psicologia propõe a possibilidade de realizar terapias comunitárias para trabalhar como não ser corrupto em um sistema que induz à corrupção.

O combate à corrupção é um grande desafio. Mesmo que se verifique que os avanços da democracia brasileira demonstrem o amadurecimento da população sobre questões que

\footnotetext{
${ }^{3}$ Estaria Janine sugerindo uma espécie de posição original, como a proposta por John Rawls em sua Teoria da Justiça?
}

Barbarói, Santa Cruz do Sul, Edição Especial n.44, p.<106-119>, jul./dez. 2015 
envolvem a corrupção, essa é uma atitude infindável em virtude da capacidade mutacional e adaptativa das patologias relacionadas à corrupção (LEAL, 2013, p. 153).

Portanto, em sendo a corrupção um fator que se prolonga ao longo do tempo, que se renova constantemente, consequentemente os impactos sociais sofridos poderão ser outros.

Desta forma, sabendo-se que a corrupção tende a diminuir o nível de eficiência governamental é preciso desenvolver e consolidar ações de combate às práticas corruptivas para que haja maior retorno dos recursos destinados às áreas da saúde e da educação, proporcionando maior bem-estar social e crescimento econômico (LOPES e TOYOSHIMA, 2013, p. 202).

Os impactos sociais da corrupção nas políticas públicas destinadas às crianças e aos adolescentes são sentidos nas áreas da saúde e da educação, mas também em outras. Seus desdobramentos, conforme acima mencionado, são infindáveis. Constata-se assim que

\begin{abstract}
nosso país necessita urgentemente de uma estrutura básica melhor e mais eficiente, saúde pública de qualidade, melhores condições de higiene e habitação, segurança pública eficaz, ensino de alto nível, onde as crianças e os jovens possam entrar em excelentes universidades, por mérito e esforço, sem serem prejudicados pela precariedade do sistema. Portanto, os controles dos recursos financeiros são indispensáveis, assim como sua eficaz fiscalização aos destinos propostos (FRATTON, 2014, p. 135).
\end{abstract}

Nesse contexto, retomando a pergunta de Alice, que caminho se deve tomar para sair daqui - do cenário de corrupção?

Acredita-se, de acordo com Moreira (2014, p. 103), que o caminho mais apropriado para a mudança dessa realidade é a educação, especialmente aquela que privilegie a formação e consolidação do caráter da criança, do adolescente e do jovem. Propiciando a renovação de valores e preparando adultos mais responsáveis e conscientes, que primem pela dignidade humana e pela cidadania. Pois,

\begin{abstract}
talvez estejamos transitando por épocas de noite escura, onde a violência, a intolerância, o individualismo, a corrupção, a xenofobia, a exploração, o consumismo, o medo, a depressão, as injustiças, as discriminações raciais, sociais e econômicas produzem um tenebroso nevoeiro que nos impossibilita enxergar para mais além onde habita a renovação ética. Talvez esse nevoeiro só possa ser dissipado se valores outros forem chamados a compor essa paragem: solidariedade, tolerância, respeito às diferenças, sede de justiça, responsabilidade social, autonomia moral. Enquanto existir um lampejo de humanidade, iremos recobrar as esperanças de construção de um mundo mais fraterno e pacífico, e para isso, torna-se imprescindível o investimento na educação moral dos indivíduos. As propostas de educação em/para os direitos humanos apelam para a construção de uma cultura de paz, de solidariedade entre os povos, de tolerância entre as nações, de respeito à liberdade, à igualdade, à fraternidade, à diversidade, mas seus atuais mecanismos de intervenção mostram-se ainda em construção (MORAIS e NÓBREGA, 2010, p. 2754).
\end{abstract}

Afinal, "por todas estas razões o capital social é importantíssimo neste processo de depuração das instâncias democráticas e suas instituições, para que permaneçam ou voltem a cumprir os pactos e compromissos civilizatórios ajustados" (LEAL, 2013, p. 189). 


\section{Considerações finais}

As diferentes percepções acerca do fenômeno da corrupção nos fazem perceber os contextos de historicidade, mutabilidade e evolução, revelando diferentes contornos, caminhos e descaminhos. No Brasil, a corrupção chega a ser apelidada de 'jeitinho brasileiro' revelando que essa patologia está presente em todas as esferas. Contudo, ao mesmo tempo, é preciso ter ciência que a corrupção é um fenômeno mundial atingindo tanto os países subdesenvolvidos como os países desenvolvidos.

Assim como atinge idosos, adultos, adolescentes e crianças. Em relação a essas duas faixas etárias iniciais estabelecem-se relações possíveis com a corrupção desde exemplos e práticas cotidianas realizadas no próprio lar e também na escola. Também em virtude de que a corrupção atinge brutamente os direitos humanos e consequentemente crianças e adolescentes que são pessoas em condição peculiar de desenvolvimento.

Portanto os impactos sociais causados pela corrupção interferem diretamente nas políticas públicas destinadas às crianças e aos adolescentes. Atingindo não só educação e saúde, mas também outras áreas como habitação e saneamento básico. Diferentes impactos sociais práticos são mostrados como os que decorrem da falta da merenda escolar, do acesso a medicamentos ou da falta de atendimento hospitalar. Mas, não há como demonstrar os reflexos infindáveis desses impactos sociais.

Por tudo isso, acredita-se que a alternativa mais apropriada para mudança desse contexto de corrupção está estreitamente vinculada à educação. É preciso que as escolas cada vez mais incentivem e ensinem a importância e necessidade da ética e da justiça nas relações sociais, promovendo a conscientização desses pequenos e jovens para que se tornem cidadãos adultos conscientes. Dessa forma, gradualmente e lentamente, será possível estreitar cada vez mais os descaminhos da corrupção e tornar o caminho das crianças e adolescentes mais sólido e promissor.

\section{Referências}

BRASIL. A responsabilidade social das empresas no combate à corrupção. 2009. Disponível em: http://www.cgu.gov.br/Publicacoes/etica-e-

integridade/arquivos/manualrespsocialempresas_baixa.pdf. Acesso em: 11 jun. 2015.

CARROL, Lewis. Alice no país das maravilhas. [s.1.]: Arara Azul, 2002. Ebook disponível em: http://www.ebooksbrasil.org/adobeebook/alicep.pdf. Acesso em: 20 jun. 2015. 
CORTELA, Mário Sérgio. Entrevistas especiais publicadas aos domingos. Zero Hora. Porto Alegre, 2015. Disponível em: <http://zh.clicrbs.com.br/rs/pagina/mario-sergio-cortella.html>. Acesso em: 20 jun. 2015.

CUSTÓDIO, André Viana. A exploração do trabalho infantil doméstico no Brasil contemporâneo: limites e perspectivas para sua erradicação. Florianópolis: [s.e.], 2006. Disponível em: <http://www.dominiopublico.gov.br/download/teste/arqs/cp007202.pdf>. Acesso em: 04 jul. 2015.

FRATTON, Elisangela Furian. A dignidade da pessoa humana e o fenômeno da corrupção no Brasil. In: LEAL, Rogério Gesta; SILVA, Ianaiê Simonelli da (Orgs.). As múltiplas faces da corrupção e seus efeitos na democracia contemporânea. Santa Cruz do Sul: EDUNISC, 2014.

GRANDESSO, Marilene; BARRETO, Miriam Rivalta (Orgs). Terapia comunitária: saúde, educação e políticas públicas. São Paulo: Casa do Psicólogo, 2007.

LACCA, Edmundo González. La corrupción y la ética. Texto disponibilizado pelo professor Rogério Gesta Leal, na disciplina Estado e Administração Pública do Programa de PósGraduação em Direito da Universidade de Santa Cruz do Sul - UNISC.

LEAL, Rogério Gesta. Patologias corruptivas nas relações entre estado, administração pública e sociedade: causas, consequências e tratamentos. Santa Cruz do Sul: EDUNISC, 2013.

LEAL, Rogério Gesta; SILVA, Ianaiê Simonelli da (Orgs.). As múltiplas faces da corrupção e seus efeitos na democracia contemporânea. Santa Cruz do Sul: EDUNISC, 2014.

LOPES, Luckas Sabioni, TOYOSHIMA, Silvia Harumi. Evidências do Impacto a Corrupção sobre a eficiência das políticas de saúde e educação nos estados brasileiros. In: Planejamento e Políticas Públicas. 2013. Disponível em:

$<$ http://www.ipea.gov.br/portal/index.php?option=com_content\&view=article\&id=20987\&It emid=7>. Acesso em: 02 jul. 2015.

MATTA, Roberto da. O jeitinho brasileiro é uma forma de corrupção? Revista de História.com.br. [s.1.]: 2009. Disponível em:

$<$ http://www.revistadehistoria.com.br/secao/conteudo-complementar/forum-sobre-corrupcaoroberto-damatta>. Acesso em: 02 jul. 2015

MORAIS, Raffaela Medeiros; NÓBREGA, Saulo de Tarso Gambarra. Educação moral e empatia: contribuições para a promoção de uma educação em/para os direitos humanos. Disponível em: <http://www.conpedi.org.br/manaus/arquivos/anais/fortaleza/3404.pdf>. Acesso em: 20 jun. 2015.

MOREIRA, Rafael Bueno da Rosa. Da improbidade administrativa decorrente de licitações públicas e suas consequências aos direitos humanos. In: LEAL, Rogério Gesta; SILVA, Ianaiê Simonelli da (Orgs.). As múltiplas faces da corrupção e seus efeitos na democracia contemporânea. Santa Cruz do Sul: EDUNISC, 2014.

PEREIRA, José Matias. Reforma do Estado e Controle da Corrupção no Brasil. In: Revista de Administração Mackenzie. São Paulo: Universidade Presbiteriana Mackenzie, 2003. Vol. 4, Ano 1. 
Pesquisa mostra que crianças podem apresentar senso de justiça aos três anos. Zero Hora. Porto Alegre, 2015. Disponível em: 〈http://zh.clicrbs.com.br/rs/vida-e-estilo/vida/bemestar/noticia/2015/06/pesquisa-mostra-que-criancas-podem-apresentar-senso-de-justica-aostres-anos-4784264.html>. Acesso em: 19 jun. 2015.

RIBEIRO, Renato Janine. Bacon, o filósofo mais corrupto. Zero Hora. Porto Alegre, 2015. Disponível em: বhttp://zh.clicrbs.com.br/rs/noticias/proa/noticia/2015/02/renato-janineribeiro-bacon-o-filosofo-mais-corrupto-4704283.html>. Acesso em: 19 jun. 2015.

RIBEIRO, Renato Janine. Como reduzir a corrupção. Jogo do poder. [s.1.], 2014. Disponível em: <http://www.jogodopoder.com/blog/politica/como-reduzir-a-corrupcao-por-renatojanine-ribeiro/\#ixzz3eb9kBIBP>. Acesso em: 19 jun. 2015.

SBT denuncia quadrilha da merenda escolar em Sergipe. NE Notícias. Aracaju, 2015.

Disponível em: < http://www.nenoticias.com.br/90376_sbt-denuncia-quadrilha-da-merendaescolar-em-sergipe-assista-agora.html>. Acesso em: 02 jul. 2015.

WOLKMER, Carlos Antonio. Elementos para uma crítica do estado. Porto Alegre: Sergio Antonio Fabris, 1990.

\section{Sobre os autores:}

Leila Viviane Scherer Hammes é Mestranda no Programa de Pós-Graduação em Direito da Universidade de Santa Cruz do Sul (UNISC) e integrante do Grupo de Estudos em Direitos Humanos de Crianças e Adolescentes (Grupeca/Unisc). Endereço eletrônico: leilavsh@gmail.com

André Viana Custódio é Pós-Doutor em Direito pela Universidade de Sevilha/Espanha, Doutor em Direito pela Universidade Federal de Santa Catarina, professor do Programa de PósGraduação em Direito - Mestrado e Doutorado da Universidade de Santa Cruz do Sul - Unisc. Endereço eletrônico: andrecusstodio@unisc.br 